\title{
Angiogenesis and inflammation in invasive carcinoma of the breast
}

\author{
A H S Lee, L C Happerfield, L G Bobrow, R R Millis
}

\begin{abstract}
Aim-To investigate the relation between angiogenesis and inflammation in invasive carcinoma of the breast.

Methods-Sections from 75 invasive carcinomas of the breast were stained using immunohistochemistry for von Willebrand factor, CD3, CD8, CD45RO, CD45RA, CD20, CD68, and c-erbB-2. Tumour vascularity was assessed by counting vessels in the three most vascular areas, and calculating the average ( $\times 400$ magnification, field $0.168 \mathrm{~mm}^{2}$ ). Each pattern of inflammation was scored semiquantitatively.
\end{abstract}

Results-The main pattern of inflammation was a diffuse infiltrate of macrophages, and to a lesser extent $T$ cells. Perivascular and perilobular clusters of $B$ and $T$ cells were noted at the edge of the carcinomas, but were less prominent than the diffuse inflammation. Diffuse inflammation, particularly macrophages, was associated with high tumour grade, tumour necrosis, large tumour size, and c-erbB-2 expression. Perivascular and perilobular inflammation also increased with tumour grade. Tumour vascularity increased slightly with intensity of diffuse inflammation (Spearman's rank correlation coefficient $r_{\mathrm{s}}=0.17, \mathrm{p}=0.08$ ), and was inversely related to perilobular inflammation $\left(r_{\mathrm{s}}=-0.23, \mathrm{p}=0.03\right)$.

Conclusions-The correlations between inflammation and vascularity were weak in this study ( $r^{2}$ about 0.04 ) and thus there was no evidence of an important relation. Discrepancies between this and other studies may be resolved by studying expression of angiogenic cytokines and proteolytic enzymes by tumour infiltrating inflammatory cells, and their relation to tumour vascularity.

(F Clin Pathol 1997;50:669-673)

Pathology Laboratory,

Imperial Cancer

Research Fund

Clinical Oncology

Unit, Guy's Hospital,

London SE1 9RT, UK

Correspondence to: A H S Lee, University Department of Pathology, Mailpoint 813, Level E, South Block, Southampton General Hospital, Southampton SO16 6YD, UK.

Accepted for publication 12 June 1997 risk of metastasis in about half the studies, the majority have shown that highly vascular carcinomas have a less favourable prognosis than tumours with low vascularity. ${ }^{1-3}$ Different patterns of inflammation may be seen in invasive carcinoma of the breast. The predominant pattern is a diffuse infiltrate in the stroma between tumour cells composed of macrophages and $\mathrm{T}$ lymphocytes. ${ }^{4-6}$ Less prominent are perivascular and perilobular clusters of $B$ and T lymphocytes. ${ }^{7}$ An association of inflammation with expression of c-erbB-2 by the carcinoma is described. ${ }^{8}$ The significance of the inflammatory infiltrate in mammary carcinoma is controversial. Different studies, even with multivariate analysis, have shown that intense inflammation in the tumour is associated with good prognosis, ${ }^{8}$ poor prognosis, ${ }^{9}$ or no effect. ${ }^{111}{ }^{11}$ It has been thought that the inflammation is a reflection of an immune response to the tumour. There is recent evidence that if this is the case the response may be ineffective, ${ }^{12}$ perhaps because of inhibition by tumour cells. ${ }^{13}$ On the other hand, inflammatory cells are a potentially important source of angiogenic cytokines. They can also release enzymes that digest the extracellular matrix and thus either facilitate vessel formation or release angiogenic factors which are present in the stroma. ${ }^{14}{ }^{15} \mathrm{~A}$ recent study $^{16}$ suggested that more highly vascular carcinomas had more intense macrophage "hotspots" within the tumour.

The aim of the present study was to assess the relations between the different patterns of inflammation and tumour vascularity in invasive carcinoma of the breast.

\section{Methods}

Seventy five consecutive invasive carcinomas of the breast were studied (the majority were also included in a previous study ${ }^{7}$ ). All patients were operated on at the Imperial Cancer Research Fund clinical oncology breast unit at Guy's Hospital. Patients with a previous carcinoma of the breast, or multiple mammary carcinomas at presentation, were excluded. The tumours were typed using Azzopardi's criteria. ${ }^{17}$ Tumours were classified as mixed if they contained more than $10 \%$ of at least two tumour types. The following were recorded for each tumour: necrosis in the invasive tumour; invasion of lymphatics or blood vessels; the number of axillary lymph nodes examined, and the number of these involved by tumour; and tumour size (measured microscopically in tumours up to $20 \mathrm{~mm}$ across, and macroscopically in larger tumours). All carcinomas were graded using the modified Bloom and Richardson method. ${ }^{18}$

The tumour vascularity and inflammation were assessed in the first surgical specimen in 
Table 1 Panel of antibodies

\begin{tabular}{|c|c|c|c|c|}
\hline Antibody & $C D$ & Specificity & $\begin{array}{l}\text { Pretreatment } \\
\text { (minutes) }\end{array}$ & Source \\
\hline von Willebrand factor & - & Endothelium & Trypsin (10) & Dako \\
\hline CD3 & CD3 & $\mathrm{T}$ cells & Microwave (30) & Dako \\
\hline CD8/144B & CD8 & $\mathrm{T}$ suppressor cells & Microwave (30) & Dr D Mason, Oxford \\
\hline UCHL1 & CD45RO & $\begin{array}{l}\text { Primed T helper cells, macrophages, } \\
\text { B cells }\end{array}$ & - & $\begin{array}{l}\text { Prof PCL Beverley, ICRF } \\
\text { London }\end{array}$ \\
\hline SN130 & CD45RA & $\begin{array}{l}\text { Naive T helper cells, macrophages, } \\
\text { B cells }\end{array}$ & - & $\begin{array}{l}\text { Dr G Janossy, Royal Free } \\
\text { Hospital, London }\end{array}$ \\
\hline L26 & $\mathrm{CD} 20$ & B cells & Microwave (15) & Dako \\
\hline PGM1 & CD68 & Macrophages & Trypsin (10) & Dako \\
\hline c-erbB-2 & - & c-erbB-2 & - & Dako \\
\hline
\end{tabular}

patients undergoing more than one procedure, to avoid changes associated with previous surgery.

Immunohistochemistry using a panel of antibodies with appropriate pretreatment (table 1), and a streptavidin-biotin technique ${ }^{7}$ was performed on sections from one selected phenol formalin fixed block from each case. We chose von Willebrand factor as the endothelial marker because in a preliminary study this gave better results than with CD31, CD34, and Ulex europaeus. The inflammatory cell markers were chosen to stain $\mathrm{T}$ and $\mathrm{B}$ lymphocytes and macrophages. Before application of the primary antibodies to von Willebrand factor, c-erbB-2, and $\mathrm{CD} 3$, normal swine serum diluted $1 / 5$ was applied for 15 minutes. In two biopsies there was only methacarn fixed tissue available, so von Willebrand factor could not be assessed, as the antibody does not work with this fixative.

\section{EVALUATION OF INFLAMMATION}

The inflammation was assessed on haematoxylin and eosin sections, and each of the sections was stained for inflammatory cell markers. Three patterns of inflammation were recognised: (1) diffuse in the stroma around and between tumour cells, (2) perivascular clusters, and (3) perilobular clusters. The intensity of each pattern of inflammatory infiltrate, (a) within and (b) at the edge of the invasive tumour, was graded as absent or minimal (0), mild (1), moderate (2), or marked (3).

Definite membrane staining for c-erbB-2 was interpreted as positive. Very weak and focal staining were scored as negative.

\section{EVALUATION OF VASCULARITY}

Vessels were assessed within the invasive carcinoma in sections stained for von Willebrand factor. The most vascular areas, or hotspots,

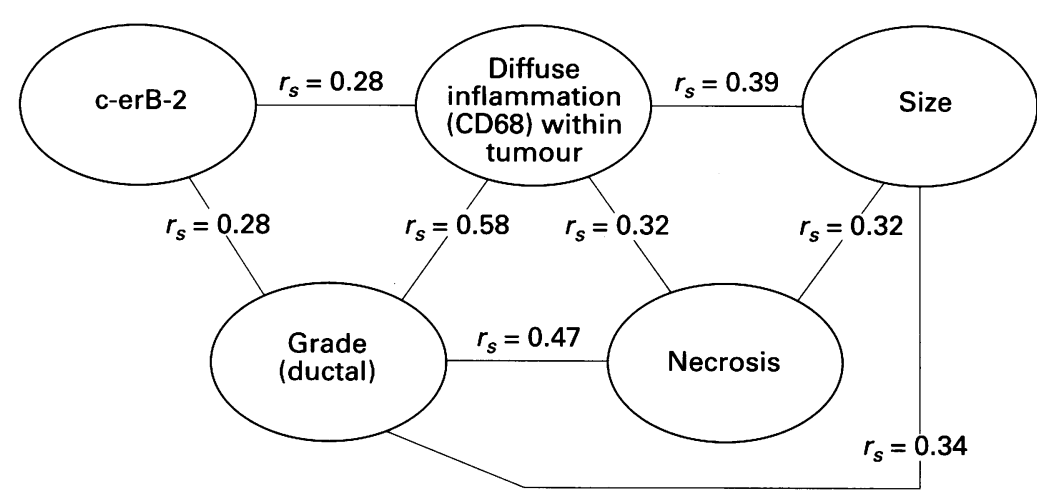

Figure 1 Correlations of the intensity of the diffuse infiltrate of macrophages with other histological features. For $r_{s}=0.28, p=0.009 ; r_{s}=0.32, p=0.003 ; r_{s}=0.39, p=0.0003$; $r_{s}=0.58, p<10^{-5}$. were identified by examination at low power. The vessel counts from the three most vascular fields $\left(0.168 \mathrm{~mm}^{2}, \times 400\right.$ magnification) were recorded, and the average calculated. No ducts or lobules, either normal or involved by carcinoma in situ, were allowed in the field. All discrete clusters or single cells stained for von Willebrand factor were counted as a vessel. A lumen was not required to count as a vessel.

The findings of a recent study noted that more vascular carcinomas had more intense macrophage hotspots within the tumour. ${ }^{16}$ This prompted us to look at the distribution of macrophages (CD68) and their relation to vessels in 42 tumours. Seven tumours, selected from those showing heterogeneous vascularity, were further studied using double immunohistochemistry. Antibody to von Willebrand factor was applied first and visualised with a streptavadin biotin technique, followed by antibody to CD68 demonstrated with an alkaline phosphatase anti-alkaline phosphatase technique. ${ }^{17}$

Comparisons between groups were made with the Mann-Whitney U method, and correlation was assessed using Spearman's rank method. The Wilcoxon signed rank test was used to analyse paired data.

\section{Results}

The 75 carcinomas were classified as 50 ductal, five tubular or cribriform, nine lobular, five mixed ductal and lobular, and one mucinous carcinoma. There were 23 grade I, 33 grade II, and 19 grade III. Axillary lymph node status was known in 71 patients, and metastatic carcinoma was present in 38 . The median tumour size was $15 \mathrm{~mm}$ (range 2 to $100 \mathrm{~mm}$ ). Vascular invasion was present in 18 and necrosis in 14 tumours. Clear membrane staining for c-erbB-2 was seen in 10 tumours (14\%).

\section{PATTERNS OF INFLAMMATION}

Diffuse inflammation was seen in 36 tumours and was the most prominent pattern of inflammation noted in this study. It was usually evenly distributed within the tumour, with accentuation at the tumour edge in some tumours. The main cell types were macrophages and $T$ cells, with the former predominant - the intensity of the diffuse infiltrate of macrophages exceeded or was similar to the intensity of $T$ cells in almost all the tumours (Wilcoxon statistic 992, $\mathrm{p}<0.001)$. Perilobular and perivascular inflammation was seen in 20 and 41 tumours respectively. Both patterns of inflammation were more prominent at the tumour edge, and 
both were mainly composed of $\mathrm{B}$ and $\mathrm{T}$ cells, with few macrophages.

Intense diffuse inflammation, especially macrophages, was associated with high tumour grade of ductal carcinomas, larger tumour size, tumour necrosis, and c-erbB-2 expression (fig 1). Intense perilobular inflammation, composed of $B$ and $T$ cells, was associated with high tumour grade of ductal carcinomas (Spearman's coefficient $r_{\mathrm{s}}=0.28$ to $0.35, \mathrm{p}=$ 0.016 to 0.003$)$, tumour necrosis $\left(r_{\mathrm{s}}=0.41\right.$ to $0.44, \mathrm{p}<0.0001)$ and larger tumour size $\left(r_{\mathrm{s}}=\right.$ 0.22 to $0.25, \mathrm{p}=0.03$ to 0.01$)$. Intense perivascular inflammation, composed of $B$ and $\mathrm{T}$ cells, was seen particularly in high grade ductal carcinomas $\left(r_{\mathrm{s}}=0.32\right.$ to $0.39, \mathrm{p}=0.006$ to 0.001 ).

\section{TUMOUR VASCULARITY}

The tumour blood vessels were either distributed evenly through the tumour (about half the tumours), or the vascularity was highest towards the periphery of the invasive tumour. Marked variation of vascularity, appreciable at low power examination, was noted in only one fifth of tumours. The median tumour vascular density was $143 / \mathrm{mm}^{2}$ (range 54 to $333 / \mathrm{mm}^{2}$ ). Vascular density was not correlated with nodal status $\left(r_{\mathrm{s}}=-0.02\right)$, histological grade $\left(r_{\mathrm{s}}=\right.$ -0.04), tumour size $\left(r_{\mathrm{s}}=-0.02\right)$, vascular invasion $\left(r_{\mathrm{s}}=0.08\right)$, or c-erbB-2 expression $\left(r_{\mathrm{s}}\right.$ $=-0.005)$.

RELATIVE DISTRIBUTION OF MACROPHAGES AND VESSELS

Macrophages were diffusely distributed through the tumour. In a quarter there was increased density of macrophages at the tumour edge, particularly in the normal tissue adjacent to the carcinoma. Macrophage

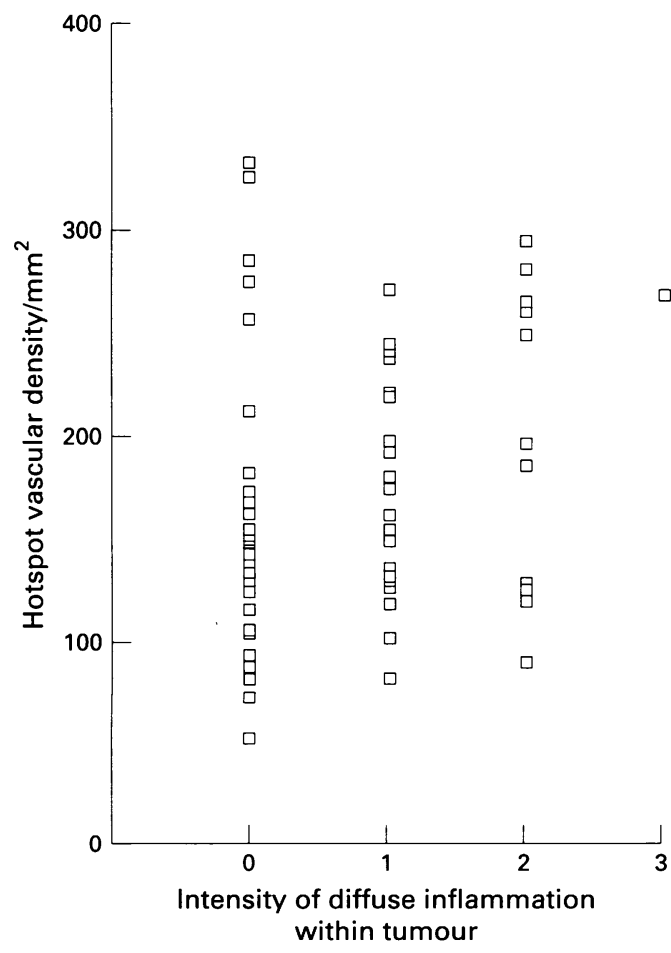

Figure 2 The hotspot vascular density and intensity of the diffuse inflammation within the tumour; $r_{s}=0.17, p=$ 0.08 .

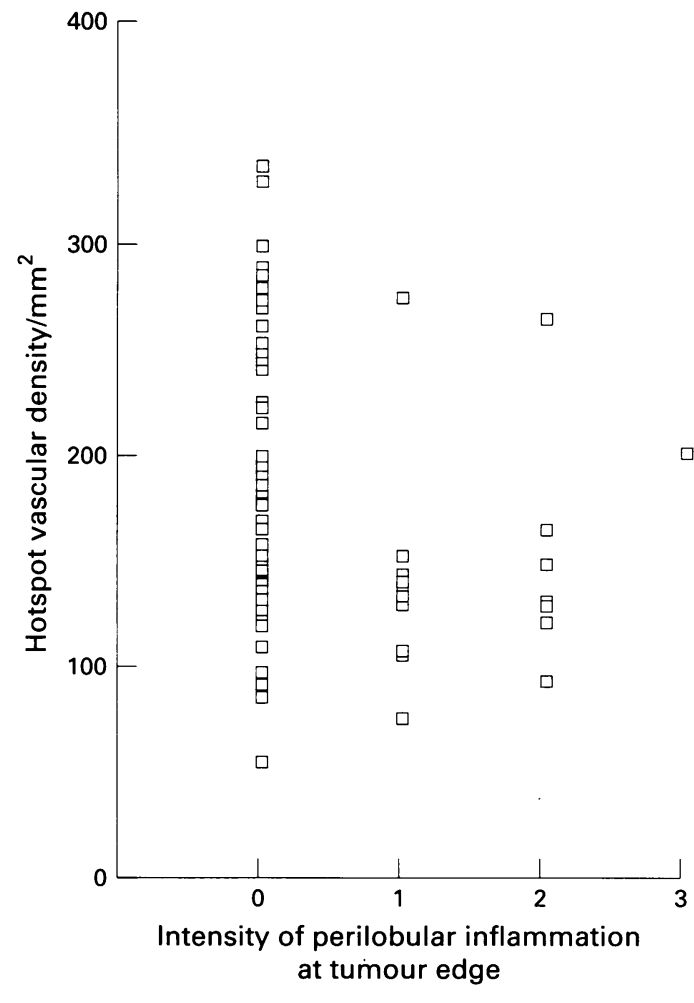

Figure 3 The hotspot vascular density and intensity of the perilobular inflammation at the tumour edge; $r_{s}=-0.23$, $p=0.03$.

hotspots were noted in a quarter of tumours, often both at the tumour edge and within the tumour. Those within the tumour were often in areas of fibrous tissue and only occasionally related to necrosis. As noted above, the blood vessels were usually either distributed evenly through the tumour or were more marked towards the tumour edge. Marked variation of vascularity was seen in only one fifth. There was no consistent pattern to the relative distributions of the vessels and macrophages.

Seven tumours, selected from those showing heterogeneous vascularity, were further studied using double immunohistochemistry for von Willebrand factor and CD68. The macrophages were diffusely distributed in all but two tumours. In one the macrophages were associated with an area of necrosis, and in one were in a central area of fibrosis. The macrophage hotspots in these two tumours were at least 7 $\mathrm{mm}$ from the vascular hotspots.

\section{VASCULARITY AND INFLAMMATION}

Increasing vascular density correlated weakly with increasing intensity of diffuse inflammation within the tumour (fig 2). This small effect was seen with $T$ cells, but not with macrophages $\left(\mathrm{CD} 3 r_{\mathrm{s}}=0.16, \mathrm{CD} 8 r_{\mathrm{s}}=0.19\right.$,

Table 2 Intensity of diffuse inflammation within tumour and hotspot vascular density (divided into tertiles)

\begin{tabular}{llll}
\hline & \multicolumn{3}{l}{$\begin{array}{l}\text { Hotspot vascular density/mm } \\
\text { (divided into tertiles) }\end{array}$} \\
\cline { 2 - 4 } $\begin{array}{l}\text { Intensity of diffuse } \\
\text { inflammation within tumour }\end{array}$ & $54-129$ & $130-174$ & $175-333$ \\
\hline 0 & 12 & 18 & 7 \\
1 & 6 & 6 & 10 \\
2 & 6 & & 7 \\
3 & & & 1 \\
\hline
\end{tabular}


CD45RO $\left.r_{\mathrm{s}}=0.14, \mathrm{CD} 68 r_{\mathrm{s}}=-0.01\right)$. We also analysed our data using Leek's method to allow comparison between the two studies. The tumours were divided by vascular density into tertiles, and the diffuse inflammation in the three groups of tumours compared. Using the overall measure obtained from haematoxylin and eosin sections, we found that the inflammation in the highest tertile was higher than that in the lower two tertiles ( $p=0.004$, MannWhitney $U$ test). However, tumours in the lowest tertile for vascularity had more diffuse inflammation than tumours in the middle tertile (table 2). Similar results were obtained for CD3 cells, with more CD3 cells in the highest tertile $(p=0.055)$. By contrast, the scores for CD68 cells were similar in the three tertiles.

Vascular density decreased slightly with increasing intensity of perilobular inflammation at the tumour edge (fig 3). This pattern was seen with all cell types except macrophages $\left(r_{\mathrm{s}}=-0.17\right.$ to -0.18$)$. Vascular density was not correlated with perivascular inflammation at the tumour edge $\left(r_{\mathrm{s}}=-0.04\right)$.

\section{Discussion}

We found three main patterns of inflammation, confirming a previous smaller study. ${ }^{7}$ The predominant pattern was a diffuse infiltrate of macrophages and $T$ cells. Perilobular and perivascular inflammation was composed of $B$ and $T$ cells and was seen particularly at the tumour edge. Most previous studies have not attempted to subdivide the inflammation into different patterns. Nevertheless, reported associations of inflammation with histological grade ${ }^{20}{ }^{21}$ necrosis ${ }^{20}$ and c-erbB-2 expression ${ }^{8}$ are consistent with our findings for diffuse inflammation.

One previous study has looked at the relation between inflammation and vascularity in invasive carcinoma of the breast. Leek et $a l^{16}$ assessed the density of macrophages in hotspots in a manner similar to the assessment of vascularity in this study. They found that tumours with vascularity in the upper tertile had higher macrophage hotspot counts (average of about 20), compared with tumours in the two lower tertiles for vascularity (both average of about 15). This difference was significant $(p=0.03)$, but small. The macrophage and vascular hotspots did not coincide. They suggested that the macrophage hotspots in the tumour centre were stimulated by hypoxia to produce angiogenic factors causing angiogenesis at the tumour edge.

We found a weak correlation between the intensity of diffuse inflammation and vascularity $\left(r_{\mathrm{s}}=0.17, \mathrm{p}=0.08\right)$. This relation was due to $T$ cells and not macrophages. There was also a weak inverse relation between perilobular inflammation at the tumour edge and vascularity $\left(r_{\mathrm{s}}=-0.23, \mathrm{p}=0.03\right)$. These correlation coefficients are small $\left(r^{2}\right.$ about 0.04$)$ suggesting if there is a relation it is of little importance. Using a method of analysis like that of Leek et $a l,{ }^{16}$ we found more intense diffuse inflammation in tumours in the highest tertile for vascularity. As with the correlation analysis, this relation was due to $T$ cells and not macrophages. Thus, despite different methods of assessing the inflammation, both studies have shown weak associations between inflammation and angiogenesis, although of different cell types. Where we differ is in the interpretation. Leek $e t$ al thought the result important. We feel the magnitude of the relation is small and therefore not of major importance.

We looked for macrophage hotspots but found the macrophages were usually diffusely distributed through a tumour, and if anything the inflammation was more marked at the tumour edge. Macrophage hotspots within the tumour were present in a minority of cases. Separate hotspots of vessels and macrophages, as described by Leek et $a l{ }^{16}$ were shown by double immunohistochemistry in two of seven tumours selected because they contained vascular hotspots. Leek at al used a more sophisticated counting method, so it is possible that we have missed a subtle relation between the distributions of macrophages and vessels. The macrophage and vascular hotspots were often far apart, and thus an important relation between the two would appear unlikely. The evenness of the distribution of macrophages in most tumours in this study, and in another study using macrophage counts, ${ }^{22}$ suggests that an overall score of macrophage density (rather than hotspot counting) is a reasonable measure of the intensity of macrophages.

By contrast with the present study, in ductal carcinoma in situ we previously found a moderately strong correlation between perivascular clusters of $B$ and $T$ cells and vascularity in the interductal stroma. ${ }^{23}$ Similar methods were used in both studies, suggesting that this comparison is valid. One potential explanation of the discrepancy with the present study is that the main pattern of inflammation associated with ductal carcinoma in situ is perivascular, whereas it is a much smaller component of the inflammation found in invasive carcinomas. Also, the increased vascularity seen in ductal carcinoma in situ is outside rather than within the carcinoma.

The absence of a strong association between the intensity of inflammation and vascularity does not exclude a possible role for inflammation in angiogenesis. It may be possible to demonstrate subtle changes with cell counts that are not apparent using inflammation scores. Also, in this study simple markers of cell type were used. For example CD68 is a panmacrophage marker that stains macrophages in different situations, and probably of different function. ${ }^{24}$ We were thus not able to distinguish quiescent, antigen presenting, phagocytic, or angiogenic macrophages. There is evidence that macrophages need to be activated before they can induce angiogenesis,${ }^{15}$ and thus only a proportion of macrophages have an angiogenic phenotype. Assessment of inflammatory cell function, rather than type, may be more meaningful.

Studies of expression of digestive enzymes, angiogenic factors, and inhibitors of angiogenesis by inflammatory and carcinoma cells, and their relation to tumour vascularity, may 
explain the absence of a relation between inflammation and vascularity in invasive carcinoma, compared with the associations found in ductal carcinoma in situ. ${ }^{23}$ Urokinase type plasminogen activator, one enzyme that has been studied in carcinoma of the breast, may be important in digesting extracellular matrix and thus promoting angiogenesis. Urokinase plasminogen activator levels (measured by enzyme linked immunosorbent assay (ELISA) on tumour extracts) correlate with tumour vascularity ${ }^{25} 26$; and urokinase plasminogen activator (assessed by both immunohistochemistry and ELISA) correlates with macrophage density. ${ }^{25}$ Unfortunately these studies did not assess the relation between intensity of inflammation and vascularity. Many angiogenic factors and inhibitors of angiogenesis can be secreted by inflammatory cells, ${ }^{14}$ fibroblasts, and endothelial cells, as well as by the carcinoma cells. Most studies of angiogenic cytokines have concentrated on expression in carcinoma cells, ${ }^{28-30}$ rather than stromal cells. ${ }^{31}$ Investigation of expression of digestive enzymes and angiogenic factors, particularly by inflammatory cells, and their relation to tumour vascularity may explain the differences in invasive carcinoma and ductal carcinoma in situ.

1 Weidner N, Semple JP, Welch WR, Folkman J. Tumor ang iogenesis and metastasis-correlation in invasive breas carcinoma. N Engl f Med 1991;324:1-8.

2 Weidner N, Folkman J, Pozza F, Bevilacqua P, Alldred EN, Moore DH, et al. Tumor angiogenesis: a new significan and independent prognostic indicator in early-stage breast carcinoma. $\mathcal{F}$ Natl Cancer Inst 1992;84:1875-87.

3 Horak ER, Leek R, Klenk N, Lejeune S, Smith K, Stuart N, et al. Angiogenesis, assessed by platelet/endothelial cell adhesion molecule antibodies, as indicator of node metasadhesion molecule antibodies, as indicator of node metas4 tases

4 Bhan AK, DesMarais CL. Immunohistologic characterisation of major histocompatability antigens and inflammatory cellular infiltrate in human breast cancer. $\mathcal{F}$ Natl Cancer Inst 1983;71:507-16.

5 Gottlinger HG, Rieber P, Gokel JM, Lohe KJ, Riethmuller G. Infiltrating mononuclear cells in human breast carcinoma: predominance of T4+ monocytic cells in the tumor stroma. Int 7 Cancer 1985;35:199-205.

6 Zuk JA, Walker RA. Immunohistochemical analysis of HLA antigens and mononuclear infiltrates of benign and malignant breast. $₹$ Pathol 1987;152:275-85.

7 Lee AHS, Happerfield LC, Millis RR, Bobrow LG. Inflammatory infiltrate in invasive lobular and ductal carcinom of the breast. Br f Cancer 1996;74:796-801.

8 Rilke F, Colnaghi MI, Cascinelli N, Andreola S, Baldini MT, Bufalino R, et al. Prognostic significance of HER-2 neu expression in breast cancer and its relationship to other prognostic factors. Int $\mathcal{F}$ Cancer 1991;49:44-9.

9 Parl FF, Dupont WD. A retrospective cohort study of histologic risk factors in breast cancer patients. Cancer 1982;50 2410-6.

10 Alderson MR, Hamlin I, Staunton MD. The relative significance of prognostic factors in breast carcinoma. $\mathrm{Br} \mathcal{F} \mathrm{Can}$ cer 1971;25:646-56.

11 Roses DF, Bell DA, Flotte TJ, Taylor R, Ratech H, Dubin $N$. Pathologic predictors of recurrence in stage (T1NOM0) breast cancer. Am $\mathcal{F}$ Clin Pathol 1982;78:817-
12 Balch CM, Riley LB, Bae YJ, Salmeron MA, Platsoucas $C D$, von Eschenbach $A$, et al. Patterns of human tumor-infiltrating lymphocytes in 120 human cancers. Arch Surg 1990;125:200-5.

13 Miescher S, Whiteside TL, Carrel S, von Fliedner V. Functional properties of tumor-infiltrating and blood lymphocytes in patients with solid tumors: effects of tumor cells and their supernatants on proliferative responses of lymphocytes. F Immunol 1986;136:1899-907.

14 Sunderkotter C, Steinbrink K, Goebeler M, Bhardwaj R, Sorg C. Macrophages and angiogenesis. $f$ Leukoc Biol 1994;55:410-22.

15 Koch AE, Polverini PJ, Leibovich SJ. Induction of neovascularization by activated human monocytes. $f$ Leukoc Biol 1986;39:233-8.

16 Leek RD, Lewis CE, Whitehouse R, Greenall M, Clarke J, Harris AL. Association of macrophage infiltration with angiogenesis and prognosis in invasive breast carcinoma. Cancer Res 1997;56:4625-9.

17 Azzopardi JG. Problems in breast pathology. London: WB Saunders, 1979.

18 Elston CW, Ellis IO. Pathological prognostic factors in breast cancer. I. The value of histological grade in breast cancer: experience from a large study with long-term follow-up. Histopathology 1991;19:403-10.

19 Cordell JL, Falini B, Erber WN, Ghosh AK, Abdulaziz Z MacDonald $\mathrm{S}$, et al. Immunoenzymatic labeling of monoclonal antibodies using immune complexes of alkaline phosphatase and monoclonal anti-alkaline phosphatase (APAAP complexes). $\mathcal{F}$ Histochem Cytochem 1984;32:219-

20 Aaltomaa S, Lipponen P, Eskelinen M, Kosma V-M, Marin $\mathrm{S}$, Alharva $\mathrm{E}$, et al. Lymphocyte infiltrates as a prognostic variable in female breast cancer. Eur $\mathcal{F}$ Cancer 1992;28A 859-64.

21 Elston CW, Gresham GA, Rao GS, Zebro T, Haybittle JL, Houghton J, et al. The Cancer Research Campaign (King's/Cambridge) trial for early breast cancer: clinicopathological aspects. Br $\mathcal{F}$ Cancer 1982;45:655-69.

22 Kelly PMA, Davison RS, Bliss E, McGee JO. Macrophages in human breast disease: a quantitative immunohistochemical study. $B r f$ Cancer 1988;57:174-7.

23 Lee AHS, Happerfield LC, Bobrow LG, Millis RR. Angiogenesis and inflammation in ductal carcinoma in situ of the breast. F Pathol 1997;181:200-6.

24 O'Laughlin S, Braverman M, Smith-Jefferies M, Buckley P. Macrophages (histiocytes) in various reactive and inflammatory conditions express different antigenic phenotypes. Hum Pathol 1992;23:1410-18.

25 Hildenbrand R, Dilger I, Horlin A, Stutte HJ. Urokinase and macrophages in tumour angiogenesis. $\mathrm{Br} \mathcal{F}$ Cancer 1995;72:818-23.

26 Fox SB, Stuart N, Smith K, Brunner N, Harris AL. High levels of uPA and PA1 are associated with highly angiogenic breast carcinomas [abstract]. $\mathcal{F}$ Pathol 1993;170:388A.

27 Visscher DW, Tabaczka P, Long D, Crissman JD. Clinicopathologic analysis of macrophage infiltrates in breast carcinoma. Pathol Res Pract 1995;191:1133-9.

28 Toi $M$, Inada $K$, Suzuki $H$, Tominaga $T$. Tumor angiogenesis in breast cancer: its importance as a prognostic indicator and the association with vascular endothelial growth factor expression. Breast Cancer Res Treat 1995;36:193 204.

29 Toi M, Hoshina S, Taniguchi T, Yamamoto Y, Ishitsuka $H$, Tominaga T. Expression of platelet-derived endothelial cell growth factor/thymidine phosphorylase in human breast cancer. Int $\mathcal{f}$ Cancer 1995;64:79-82.

30 Fox SB, Westwood M, Moghaddam A, Comley M, Turley $\mathrm{H}$, Whitehouse $\mathrm{RM}$, et al. The angiogenic factor plateletderived endothelial growth factor/thymidine phosphorylase is up-regulated in breast cancer epithelium and endothelium. Br $\mathcal{F}$ Cancer 1996;73:275-80.

31 Visscher DW, DeMattia F, Ottosen S, Sarkar FH, Crissman JD. Biologic and clinical significance of basic fibroblast growth factor immunostaining in breast carcinoma. Mod Pathol 1995;8:665-70. 